\title{
Words and Music
}

The present volume of ELOPE features ten papers focusing on various aspects of the relationship between words and music. Five of them were submitted by the participants at the Words and Music conference, which was held at the Faculty of Arts of the University of Maribor in April of 2014. While the conference itself inspired the choice of theme for this issue, the topic was obviously intriguing enough to attract submissions from other scholars as well.

There is a long-standing debate about the nature of the relationship between music and words, as illustrated by the following two quotes: "Music is the universal language of mankind" (Longfellow 1835) and "Though music be a universal language it is spoken with all sorts of peculiar accents" (Shaw 1890, 91). It is thus not surprising that views on the nature of the relationship between the two differ and that scholars from various disciplines find it a fascinating topic to explore. With the exception of two contributors who are also musicians, the others are linguists and language teachers, literary scholars and translators. The starting point of their research is thus usually language, and a somewhat stronger emphasis is placed on words than on music. Despite the common thread of words, music and, to a considerable extent also culture, running through this issue, I decided, in the interest of coherence, to divide the papers into four sections according to their focus on linguistic analysis, literature, language teaching or translation.

\section{Language}

The language section consists of two papers examining the link between words and music from different perspectives: lexical, social and semiotic.

In the first of these papers, entitled "The Language in British and Slovene Football Anthems," Agata Križan explores the genre of football anthems. She focuses first on the functions and social role of football anthems and then turns to a detailed linguistic analysis of them. Football anthems, which may be set to existing melodies (from popular musicals, patriotic songs, etc.) or created anew, primarily serve to express a feeling of collective identity, solidarity and the passionate support of fans for their clubs. Sung in unison, they create a powerful performance. The language, which is fairly simple, nevertheless carries very strong emotions and, at the same time, reflects the fans' social values and ideology. The linguistic analysis, based on Martin and White's appraisal model (2005), explores primarily the evaluative language of the anthems and finds the interpersonal meanings to be realized through a whole range of such linguistic elements as repetitions, attitudinal lexis, quantification, enhancement and the like. Despite their seeming simplicity, football anthems are by no means chosen randomly; rather, they are a careful combination of linguistic and musical elements serving the purpose of authentic fandom bonding. This applies to both British and Slovene football anthems and is, in that sense, a crosscultural phenomenon.

Katja Plemenitaš paper, "Songs as Elements in the Generic Structure of Film Musicals," on the other hand, addresses the issue of words and music from a different perspective, i.e. within the framework of systemic-functional grammar (Halliday 1989). Musicals are by definition 
multimodal in that they contain popular music, songs, dance and, optionally, spoken dialogue. Plemenitaš is primarily interested in songs and the function that they play in film musicals as opposed to that in non-musical films. She finds several differences between the use of diegetic and non-diegetic songs in both genres, which are manifested through the register variables of field, mode and tenor. Her analysis of the popular American TV musical High School Musical 2 in terms of the songs' evaluative nature, the degree of their integration into the musical and of their potential to further the musical's narrative independently represents a solid theoretical basis for further research of this genre.

\section{Literature}

As for the link between literature and music, not all literary critics agree that song lyrics can be considered poetry. Some feel that they are too simple to reach the technical and emotional depths of poetry. Others point out that many of the greatest poets in the English language wrote lyrics expressly intended to be accompanied by music and that these works do reach the level of great poetry. Yet others argue that music can contain many of the elements usually associated with poetry, such as sound effects, imagery, and even metaphor, and that these, when combined with lyrics, add up to a sound poem. The four papers included in this section span different genres - not just poetry - and discuss various ways in which words and music interact in them.

Victor Kennedy's paper, "Musical Metaphor in the Poetry of Wallace Stevens," examines Stevens's use of metaphor comparing music to poetry in "Peter Quince at the Clavier," "The Idea of Order at Key West," and "The Man with the Blue Guitar." He places special emphasis on this last work, a very intriguing poem, inspired by a Picasso painting and written in the stream-of-consciousness manner, in which the poet uses the metaphor of a musical instrument as a transformational symbol of the imagination. Musical metaphor is in fact central to Stevens's poetry both in terms of theme and structure. Kennedy discusses notions such as creative imagination, perceived reality, the "timeless or spatialized moment" and the replacement of religion by poetry. He also describes Stevens's innovative use of ekphrasis and reversal of metaphoric terms to explore some of the main concerns of the modernist movement. He considers "The Man with the Blue Guitar" to be one of the most influential poems of the 20th century and concludes by arguing that Stevens's work from 1915 to the late 1930s already anticipated postmodernist ideas.

The influence of music is not limited to the use of musical metaphors in literature, but may extend into other genres based on literary works, as shown by Tomaž Oničs paper "Music becomes Emotions: Musical Score in Two Productions of A Streetcar Named Desire". The author compares the musical scores in two productions based on Tennessee Williams's play, the classic 1951 Kazan film and the more recent and less traditional 2008 stage production by the Slovene National Theatre in Maribor. While the former faithfully follows Williams's dramatic plot, the latter is more of a psychoanalytic interpretation of the play and focuses not so much on the dramatic action, but rather on the turbulent mental state of the main character, Blanche. The musical scores are adapted accordingly. The film soundtrack is harmonized with the dramatic action; it is predominantly diegetic (Cohen 2011) and could be analyzed in terms of music functions according to Pendergast (1992, 213-22). On the other hand, the music in the stage production is for the most part non-diegetic, electronic and overshadowed by visual effects. Onič sees the choice of music in the Maribor production as better suited to capturing the mood of the psychoanalytic interpretation of the play than the classic jazz score used in the film. In both productions, however, music represents a powerful source of emotions with which the audience can identify. 
Another aspect of the relationship between words and music is presented in Marcin Stawiarski's paper "Eccentric Voices and the Representation of Vocal Virtuosity in Fiction: James McCourt's Mawrdew Czgowchwz" and is connected with the depiction of a fictional opera character in a novel. Stawiarski examines the representation of vocal virtuosity and musical eccentricity in fiction, focusing on the role of the voice as it is presented in McCourt's novel. Mawrdew Czgowchwz tells the story of an opera singer whose voice is related to extravagance and fanaticism, so that it echoes violence, conflict and even dictatorial regimes. Stawiarski argues that the notion of eccentricity is a fundamental mode of representing music in literature, and also that eccentricity rubs off on the very structure of the text, so that it leads to singular forms of biographical writing. In McCourt's novel, the stylistic features of the text demonstrate a hyperbolic use of language including lists, foreign vocabulary, and neologisms, or nonce-words, which create a cornucopia of the tongue-twisting effects of linguistic musicality.

Oana Ursulesku's paper "In Between the 'Brows': the influx of highbrow literature into popular music," in contrast, is a case study of the influence of "serious" literature on several popular song writers. The global phenomenon of popular music from the middle of the 20th century was one of the factors in the merging of what had previously been divided into high and low culture. Popular songwriters began to include in their songs references to literary works traditionally thought of as "highbrow." Ursulesku examines examples from various musical genres that refer to or were inspired by works from the Anglo-American literary canon. Kate Bush's 1989 single "The Sensual World" was originally meant to quote the exact words from Molly Bloom's soliloquy in James Joyce's Ulysses, but the Joyce estate refused to grant permission, so the song was recorded with lyrics that Bush wrote herself, inspired by Molly Bloom's words on the page. Other examples include David Bowie's 1974 album Diamond Dogs, based on George Orwell's 1984, and references to highbrow literature in songs, song titles, and album titles by bands such as The Smiths, The Cure, and Iron Maiden. Ursulesku shows how ideas from literary works are transposed and adapted in the lyrics of popular songs, giving credit to musicians not only as innovative creators of new works of art, but as creators of adapted works of art that can be intertextually read as part of the artist's cultural heritage.

\section{Teaching English Language and Literature}

The next section examines the practical implications of words and music for teaching and learning English.

Jason Blake's paper “The Ironic Musical Edge: Using Songs to Present and Question Myths" focuses on teaching culture courses, more specifically Canadian culture with which he is, a native of Canada, intimately familiar. He offers the use of popular ironic songs in the classroom as a fresh alternative to the traditional approach of feeding students fragmented factographic information. While the former usually equips students with mostly oversimplified, stereotypical knowledge about the country and its national myths, Blake's approach is aimed at questioning those myths and thus providing a more realistic, multifaceted and up-to-date picture of a country's culture. A good example of an ironic song which could be used to challenge students' intellectual curiosity is "Canada Is Really Big". The song is characterized not only by a mismatch of tunes and lyrics, but the lyrics themselves contain elements of semantic ambiguity, irony and subtle undertones. The students are challenged to recognize irony (the ability to do so being one of the surest tests of intelligence and sophistication (Holman 1972)). This requires not only a very careful reading, enhancing their reading skills, but also provides an opportunity for them to learn about the 
national self-image and other relevant references with regard to Canada's culture and society. It goes without saying that Blake's approach of using contemporary popular music, with which students identify more readily than with historical accounts, also carries a high motivational value.

Another author dealing with the use of songs in the classroom is Kirsten Hempkin. As the title of her paper "Exploring Student Attitudes to the Refugee Crisis: Songs on Migration" suggests, she is tackling a most topical issue currently occupying Europeans (including Slovenes) - the influx of refugees/migrants from Syria and other war-torn countries. The widespread negative attitudes to this crisis made her think of what language teachers could do to counter the prejudice and even hate speech surrounding us. She believes that it is our responsibility to raise students' awareness in this regard and finds songs of migration to be a perfect tool to help them understand the issues involved. The vast array of activities that she presents are intended to help students broaden their horizons in terms of greater tolerance toward other cultures and also to help develop empathy toward the underprivileged and the suffering. Introducing songs of migration into the classroom presents a very valuable learning opportunity in several ways: more broadly, it teaches students about the historical, social and geographical context in which the songs were created as well as about human rights issues, while, more specifically, it provides an opportunity for them to analyze the language idiom and its interplay with music. In this way songs, which are generally well received by students, may be beneficial also to language and literature learning. Above all, however, the value of Hempkin's approach is in its emphasis on the need for intercultural education and in the wealth of song-based teaching materials and activities included in her paper.

\section{Translation Studies}

If the relationship between words and music seems complex in the same language, then this is even more so in translation, where two languages as well as related cultural contexts have to be taken into consideration. Both papers in the translation section can be judged as unique: Andrej Stopar's "Mamma Mia, a Singable Translation" in that it brings the first ever analysis of translating singable texts from English to Slovene, and Giovanni Nadiani and Chris Rundle's paper "Pianure Blues: From the Dialect of the Plains to the English of the Blues" because of its very original and rather unorthodox approach.

In the absence of much research in the area of multimodal materials such as musicals, Andrej Stopar undertakes the challenging task of comparing the original English production of Mamma Mia! (1999) with its Slovene translation (2015) on different linguistic levels. He designs a very detailed methodology in order to identify and quantify the changes that were made during the process of translating English lyrics into Slovene. He finds that a necessary condition for a translation to be singable is a prosodic match of the source text (ST) and of the target text (TT), while in terms of lexis, structure and poetic properties there is room for minor modifications. These are achieved primarily through the translation strategies of paraphrasing, omission and addition, and are given priority over word-by-word translation. The main function of translation is therefore a singable text, which is in accordance with the Skopos theory (1978), centered on the functional properties of the ST and the TT. In the translation examined, the prosodic equivalence was achieved perfectly; moreover, despite a few contextual and cultural adaptations, both the storyline and the artistic value of the musical were preserved.

Giovanni Nadiani and Christopher Rundle's contribution is a reflection on the creative process involved in their literary-musical collaboration entitled Pianure Blues. Strictly speaking, what 
Nadiani, a poet and a native speaker of the Italian Romagnolo dialect, and Rundle, an American professor and translator living in Italy, do transcends the boundaries of translation. They call it "trans-staging," where on the one hand they transpose the Romagnolo poems into English and perform them as blues songs and on the other, transpose and perform songs from the AngloAmerican blues/roots/folk tradition in the Romagnolo dialect. They thus inhabit the role of writers/poets, performers and translators. Their inspiration comes from the parallels that they see between the topography of the Po valley plains (pianure in Italian) and of the Mississippi delta. The two iconic landscapes, associated with the experience of harsh lives, poverty and nostalgia, represent common ground for both. This accounts, for instance, for a song that may be blues in musical terms, but contains lyrics that are essentially inspired by the Romagna landscape. While the music embodies a universal archetypal experience, the dialect allows for a more authentic, genuine expression of one's identity in a way that would not be possible in standard Italian. Translating each other's voices and stories, Nadiani and Rundle use their poetics and live performances to bridge the gap between the seemingly two distant, but in fact close cultures, as well as between a "minority" dialect and "global" English, all of which gives their idiosyncratic multimodal, interdisciplinary and intercultural approach added value.

The approaches to words and music employed by the featured authors vary and yet complement each other - a reflection of the highly complex nature of the phenomenon under investigation. It is hoped that this volume can shed light on the way in which words and music intertwine and influence each other, how they are enmeshed with culture, expressing emotions, identity and more, and how they also "define us as human" (Patel 2008, 3). Works such as this issue of ELOPE can make a significant contribution to our understanding of the highly intricate language-music interface, which is and will continue to be a richly fertile theme for interdisciplinary research.

Nada Šabec, University of Maribor

Editor of ELOPE Vol. 13, No. 1

\section{References}

Cohen, Annabel. 2011. "Music as a Source of Emotion in Film." In Music and Emotion: Theory and Research, edited by Patrik N. Juslin and John A. Sloboda, 249-79. New York: Oxford University Press.

Holman, C. Hugh. 1972. A Handbook to Literature. Indianapolis: Odyssey.

Longfellow, Henry W. 1835. Outre-Mer: A Pilgrimage beyond the Sea. New York: Harper and Brothers.

Martin, James R., and Peter R. White. 2005. The Language of Evaluation. Appraisal in English. London: Palgrave Macmillan.

Patel, Aniruddh. 2008. Music, Language and the Brain. Oxford, New York: Oxford University Press.

Pendergast, Roy M. 1992. Film Music A Neglected Art. A Critical Study of Music in Films. New York: W. V. Norton \& Company.

Shaw, George B. 1949. (Reprint of 1932 edition). Music in London: 1890-94. Vol 1. London: Company Limited. 